\title{
Effects on Dentin Treated with Eluted Multi-Mineral Varnish In Vitro
}

\author{
Robert L. Karlinsey, ${ }^{\mathrm{a}, *}$, Allen C. Mackey and Craig S. Schwandt ${ }^{\mathrm{b}}$ \\ ${ }^{a}$ Indiana Nanotech, 351 West $10^{\text {th }}$ Street, Suite 309, Indianapolis, Indiana, 46202, USA \\ ${ }^{b}$ McCrone Associates, Inc., 850 Pasquinelli Drive, Westmont, IL 60559-5539, USA
}

\begin{abstract}
Purpose: The purpose of this pilot study was to assess the non-contact effects of a NaF varnish on the morphology and elemental compositions of sound and demineralized dentin in an in vitro $\mathrm{pH}$ cycling model.

Methods: $3 \mathrm{~mm}$ diameter dentin cores were extracted from bovine teeth, mounted in acrylic rods, and ground and polished. Sound and demineralized (in $10 \mathrm{~mL}$ unstirred $50 \%$ citric acid $(\mathrm{pH}=1.2)$ for two minutes) specimens were divided into four groups $(\mathrm{N}=6)$ corresponding to treatments with either water (control group) or non-contact Vanish ${ }^{\circledR} 5 \% \mathrm{NaF}$ White Varnish with tri-calcium phosphate (3M ESPE). For the non-contact varnish group, one $0.50 \mathrm{ml}$ unit-dose was applied to acrylic rods and positioned in the same stopper as three dentin specimens. The four groups were then cycled in a regimen consisting of three rounds of one-hour treatments with each round followed by immersion in a three-minute static acid challenge $(0.3 \%$ citric acid, $\mathrm{pH}=3.8)$. For each one-hour treatment immersion the test groups were immersed in distilled water. The specimens were thoroughly rinsed with distilled water after each treatment and after each acid challenge. After the last challenge, specimens were rinsed with distilled water and immersed in artificial saliva (AS) overnight. All treatments, acid challenges and immersion in AS solution were performed in an incubator set at $37^{\circ} \mathrm{C}$. After three days, the specimens were assessed using scanning electron microscopy (SEM) and energy-dispersive X-ray spectroscopy (EDS).
\end{abstract}

Results: SEM and EDS results demonstrated the non-contact varnish group can provide mineralization benefits relative to the control group for both sound and demineralized dentin substrates. Depositions from mineral eluting from the varnish developed on the intertubular and intratubular regions alike, with the most prominent depositions appearing on initially demineralized dentin.

Conclusions: In this observational study, acid-resistant mineral depositions were produced on the sound and dentin surfaces without direct application from a multi-mineral varnish containing fluoride, calcium and phosphate.

Keywords: $\mathrm{TCP}, \mathrm{NaF}, \mathrm{pH}$ cycling, remineralization.

\section{INTRODUCTION}

Dentin hypersensitivity is a common condition reported in patients of all ages and both genders. Though there is wide variation in assessments, some studies show its prevalence in up to $57 \%$ of the population. [1,2] A survey of dentists in the United Kingdom reported that approximately $25 \%$ of their patients manifest hypersensitivity, with severe hypersensitivity affecting about $10 \%$ [3]. Common approaches in addressing dentin hypersensitivity include the use of topical preparations containing desensitizing agents, agents that promote depositions on the dentin, or barrier-like materials that physically laminate the affected tooth [1-3]. In the present study, we focus our attention on the use of a fluoride varnish.

The United States Food and Drug Administration formally recognizes cavity varnishes indicated for the treatment of sensitive teeth and especially for use on exposed dentin and root; additionally, varnishes are approved for the appli

*Address correspondence to this author at the Indiana Nanotech, 351 West $10^{\text {th }}$ Street, Suite 309, Indianapolis, Indiana, 46202, USA;

Tel: +1-317-385-1578; Fax: +1317-278-4102;

E-mail : rlk.nanotech@gmail.com cation to a cavity prior to insertion of restorative materials in order to prevent penetration into the dentin tissue [4]. Originally, fluoride varnishes were developed for use in Europe, Scandinavia and Canada in the 1960s with the purpose of extending the contact time of fluoride with the dentition, and their use has since continued to expand throughout the world [5]. Though not cleared for use as an anti-caries agent in the United States, fluoride varnishes are recognized as an effective therapeutic for not only hypersensitivity but also against the caries experience [6].

In vitro evaluation methods have been used to explore the potential of various agents and preparations in the occlusion of patent tubules [7-11]. The use of such models provides insight into modes of action, and in turn, this ultimately helps shape clinical expectations. The modes of action typically involve the ability to protect or form a smear layer, or occlude dentin tubules through the formation of insoluble or acid-resistant mineral.

The present pilot study explores the mineralization of sound and demineralized dentin treated with either a control group (i.e. distilled water) or a $5 \% \mathrm{NaF}$ varnish containing a calcium phosphate material (Vanish ${ }^{\circledR}$ Varnish with TCP, 
3M ESPE, St. Paul, MN, USA). But instead of applying the varnish directly to the surfaces of the dentin (i.e. direct contact), which may produce physical barriers due to the varnish matrix (e.g. rosins), in the present study we utilized a noncontact design to encourage depositions from only watersoluble agents, such as fluoride, calcium and phosphate. This design involves applying varnish to specimen-free acrylic rods and then positioning these rods near separate rods containing dentin specimens during immersion in simulated saliva. Instead of physical barriers produced from the varnish rosins, the proposed design probes depositions and/or occlusions arising from mineral elution. Although other studies evaluating the direct application of varnishes on tooth specimens have been performed [12-14], to the best of our knowledge, a study of this kind has not been explored previously. Potential depositions and/or occlusions arising from mineral elution in this in vitro study might have clinical implications particularly within regions of the oral cavity that have been inadvertently missed or not retained during varnish application. Currently there are many $5 \% \mathrm{NaF}$ systems commercially available, with many now supplemented with additional mineralizing agents such as calcium and phosphate. For this study we selected the Vanish ${ }^{\circledR}$ varnish system for three reasons: 1) its flow and materials properties have been designed to provide sustained release of ions not only to the contacted tooth but also within the oral cavity, 2) it is supplemented with an innovative form of tricalcium phosphate [15], and 3) it is one of the most widely used and/or recognized varnishes by dental practitioners. The aim of this exploratory study was to determine whether this $5 \%$ $\mathrm{NaF}$ varnish could mineralize dentin substrates through noncontact means better than a fluoride-free control. This observational study includes treatments, acid challenges and remineralization events and included both sound and demineralized dentin. Morphology and chemical composition of the sound and demineralized dentin cycled in the model and treated with either the control group or the fluoride varnish groups were subsequently investigated using field emission scanning electron microscopy (FESEM) and energydispersive X-ray spectroscopy (EDS).

\section{MATERIALS \& METHODS}

\section{Dentin Specimen Preparation}

Tooth cores $3 \mathrm{~mm}$ in diameter were drilled using a hollow-core diamond drill bit (Diamond Drill Bit \& Tool, Omaha, NE, USA) by cutting perpendicularly into the labial surfaces of bovine molars and incisors. The cores were mounted into the ends of hollowed out acrylic rods (McMaster-Carr, Chicago, IL, USA) using DuraLay mounting resin (Reliance Dental Mfg. Co., Worth, IL, USA). Each specimen was ground by hand with 600 grit $\mathrm{SiC}$ sandpaper (LECO Corporation, St. Joseph, MI, USA) under water cooling using a Spectrum System 1000 Grinder/Polisher (LECO Corporation) set to $300 \mathrm{rpm}$. The specimens were ground down extensively so as to remove all the enamel and expose the underlying dentin. Then, each specimen was polished by hand for 1 minute using $3 \mu \mathrm{m}$ diamond compound in conjunction with microid extender solution (LECO Corporation). The presence of dentin was confirmed by optical microscopy using a LM247AT microhardness tester (LECO Corporation). For initial demineralization in order to expose
Table 1. Sample ID's and Sample Descriptions for Dentin Specimens Evaluated in this Study

\begin{tabular}{|l|c|}
\hline \multicolumn{1}{|c|}{ Sample Description } & Sample ID \\
\hline \hline Baseline sound dentin & A \\
\hline Baseline demineralized dentin & B \\
\hline Sound dentin $\mathrm{pH}$ cycled with water & $\mathrm{C}$ \\
\hline Sound dentin $\mathrm{pH}$ cycled with non-contact varnish & $\mathrm{D}$ \\
\hline Demineralized dentin $\mathrm{pH}$ cycled with water & $\mathrm{E}$ \\
\hline Demineralized dentin $\mathrm{pH}$ cycled with non-contact varnish & $\mathrm{F}$ \\
\hline
\end{tabular}

dentin tubules, specimens were immersed in $10 \mathrm{~mL}$ of unstirred $50 \%$ citric acid $(\mathrm{pH}=1.2)$ (Fisher Scientific, Pittsburgh, PA, USA) for 2 minutes and then rinsed with distilled (DI) water to remove any residual smear layer. For those specimens that were demineralized, the presence of exposed tubules post-acid etch was confirmed by optical microscopy.

\section{Artificial Saliva \& Acid Challenge Solutions}

The artificial saliva (AS) was prepared as follows with all chemicals obtained from Fisher Scientific. In 2 liters of DI water, $0.7084 \mathrm{~g}$ calcium nitrate was added. After complete dissolution, $0.2450 \mathrm{~g}$ potassium phosphate monobasic was added. After complete dissolution, $19.383 \mathrm{~g}$ potassium chloride was added. After complete dissolution, $8.56 \mathrm{~g}$ cacodylic acid was slowly added and allowed to mix for at least 15 minutes. Slow addition of concentrated $\mathrm{HCl}$ was added to adjust the $\mathrm{pH}$ to 7.0. The resulting solution then contained $1.25 \mathrm{mM} \mathrm{Ca}^{2+}$, $5.4 \mathrm{mM} \mathrm{PO}_{4}{ }^{3-}, 20.4 \mathrm{mM} \mathrm{K}^{+}, 24.5 \mathrm{mM} \mathrm{Cl}^{-}$and $6.5 \mathrm{mM} \mathrm{Na}^{+}$.

Solution used for the acid challenge was prepared by adding $0.3 \%$ citric acid to distilled water, followed by $\mathrm{pH}$ adjustment to 3.8 using concentrated $\mathrm{NaOH}(\mathrm{aq})$.

\section{Test Groups \& Treatments}

Sound and demineralized specimens were prepared for the $\mathrm{pH}$ cycling study. Table 1 summarizes the six study groups for the present study. Samples A and B refer to baseline sound and demineralized dentin and did not undergo $\mathrm{pH}$ cycling. Samples C and D refer to initially sound dentin and Samples E and F refer to initially demineralized dentin. These four groups were then evaluated in the $\mathrm{pH}$ cycling model discussed below.

Initially sound and initially demineralized dentin were then treated with one of two possible treatments (Table 1, samples $\mathrm{C}$ through $\mathrm{F}$ ): a distilled water control treatment and a non-contact varnish treatment comprising $5 \% \mathrm{NaF}$ and functionalized tricalcium phosphate (3M ESPE Vanish ${ }^{\circledR}$ Varnish with TCP) $[12,15]$. Each treatment $(\mathrm{N}=6)$ was divided into two subsets of three dentin specimens. For the non-contact varnish treatment, one $0.50 \mathrm{ml}$ unit-dose was applied to acrylic rods and positioned in the same stopper as three dentin specimens as shown in Fig. (1a). In this study, varnish was not applied to the dentin specimens.

\section{pH Cycling Model}

The daily cycling regimen used on samples C, D, E and F is summarized in Table 2 and consisted of three rounds of 

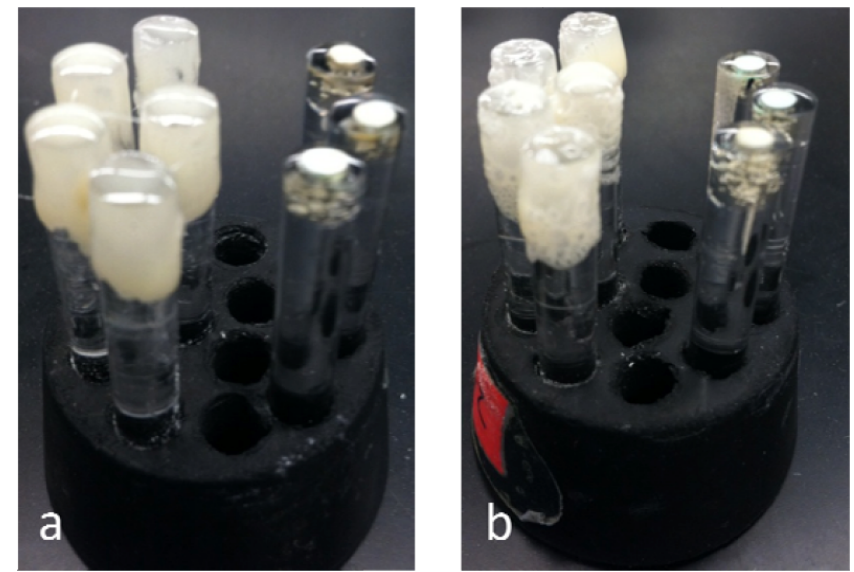

Fig. (1). Photographs of non-contact varnish specimens contained in stoppers with varnish applied to acrylic rods before (a) and after (b) each of the three daily inverted immersions in distilled water. In each photograph, the acrylic rods are on the left-hand side, while the dentin specimens are embedded in separate acrylic rods on the right-hand side. The varnished acrylic rods are removed from the stopper during acid challenges and overnight immersions in the artificial saliva mineral mix.

Table 2. Outline of Daily Events and Duration in the ThreeDay pH Cycling Model

\begin{tabular}{|c|c|}
\hline Event & Duration \\
\hline \hline Treatment \#1* & 1 hour \\
\hline Acid Challenge \#1 & 3 minutes \\
\hline Treatment \#2 & 1 hour \\
\hline Acid Challenge \#2 & 3 minutes \\
\hline Treatment \#3 & 1 hour \\
\hline Acid Challenge \#3 & 3 minutes \\
\hline Artificial Saliva, $\mathrm{pH}=7.0$ & Overnight \\
\hline
\end{tabular}

* On Day One, Specimens were Pre-Conditioned for one Hour in Artificial Saliva Prior to the first Treatment

one-hour treatments with each round followed by immersion in a three-minute static acid challenge $(0.3 \%$ citric acid, $\mathrm{pH}$ $=3.8$ ). For each one-hour treatment immersion the test groups were immersed in distilled water, with the ensuing appearance of the varnished acrylic rods shown in Fig. (1b). The specimens were thoroughly rinsed with DI water after each treatment and after each acid challenge. After the last challenge, specimens were rinsed with distilled water and immersed in AS overnight. Instead of positioning the specimens with dentin surfaces facing upwards, the specimens were inverted for the treatment, acid challenge and AS periods to diminish the possibility of deposits from settling onto the dentin surfaces or within the tubules. In this $\mathrm{pH}$ cycling model, all treatments, acid challenges and immersion in AS solution were performed in an incubator set at $37^{\circ} \mathrm{C}$. The treatment and AS immersion were magnetically agitated at $300 \mathrm{rpm}$. Fresh citric acid solution was measured out at the beginning of each day and the same solution was used for all three challenges. AS solution was refreshed daily, and fresh varnish and acrylic rods were used for each non-contact varnish group treatment per day. After three days, the specimens were imaged using FESEM.

\section{Dentin Analysis via FESEM and EDS}

The cycling regimen was performed at Indiana Nanotech (Indianapolis, IN, USA), after which coded samples were sent for blinded, independent analysis at McCrone Associates, Inc (Westmont, IL, USA). After evacuation, FESEM images of carbon-coated dentin samples were then collected using a JEOL JSM-7500F cold cathode field emission scanning electron microscope. Secondary electron images were collected at $10 \mathrm{kV}$ at various magnifications and energy-dispersive X-ray spectroscopy (EDS) were performed on two specimens from each group (one from each subgroup). The area of the beam used to collect EDS data was approximately $0.04 \mu^{2}$. The reported error for these data were determined using proprietary curve fitting equations in the Thermo Fisher (Waltham, MA, USA) EDS software and are not due to analyses of multiple specimens.

\section{Sample Size and Observational Differences}

Due to the exploratory nature of this study, we note that a relatively small number of specimens were used and that the EDS data collected from this study were not analyzed for statistical differences. As such, the quantitative data discussed below do not necessarily imply significant differences exist.

\section{RESULTS}

Representative baseline sound and initially demineralized bovine dentin at 3,000x (top row) and 20,000x (bottom row) magnification are shown in Fig. (2). Fig. (2a and 2b) images for sound dentin (Sample A) reveal the absence of a thick smear layer and this allows visual identification of mineralized dentin tubules. Additionally, these SEM images reveal the specimen preparation conditions produced smooth surfaces. The elemental analyses in Tables $\mathbf{3}$ and $\mathbf{4}$ for the intertubular and intratubular regions of sound dentin show calcium contents were between $32 \%$ and $37 \%$, the phosphorous contents were between $15 \%$ and $17 \%$ and the magnesium contents were about $1 \%$. Inter- and intratublar oxygen (about $34 \%$ and $32 \%$, respectively) and carbon (about $15 \%$ and $12 \%$, respectively) fractions were also detected.

Baseline initial demineralization (Sample B) leads to exposure of patent tubules several microns in diameter (Figure $2 \mathrm{c}$ and $2 \mathrm{~d}$ ), as well as relative shifts in elemental weight fractions compared to sound dentin. For demineralized dentin, inter- and intratubular calcium (about 32\% and 57\%, respectively), phosphorous (about $15 \%$ and $21 \%$, respectively), magnesium (about $0.5 \%$ and $0.4 \%$, respectively), oxygen (about $15 \%$ and $7 \%$, respectively), and carbon (about $36 \%$ and $14 \%$, respectively) were detected.

FESEM images of initially sound dentin cycled with either distilled water (Sample C) or non-contact varnish (Sample D) are shown in Fig. (3). In contrast to sound dentin treated with the eluted constituents of the varnish, the perimeters of the dentin tubules are readily observed. The element analyses for Samples C and D listed in Tables $\mathbf{3}$ and 4 show comparable weight fractions in both the inter- and intratubular dentin regions, with the exception of fluorine which was only detected in Sample D.

Representative low and high magnification FESEM images for initially demineralized dentin cycled with either 

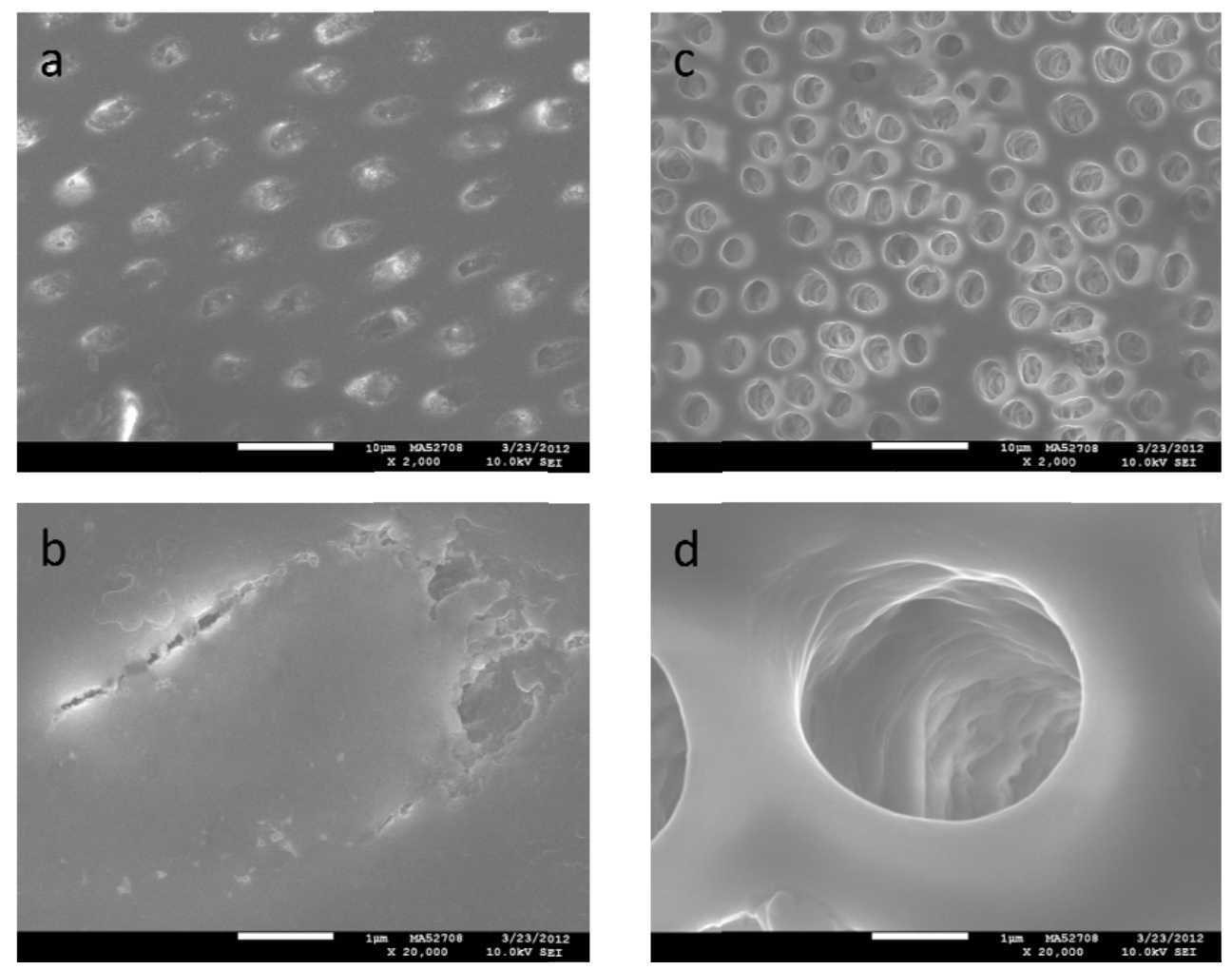

Fig. (2). SEM images of sound $(a, b)$ and demineralized (c, d) bovine dentin at 2,000x and 20,000x. The white scale bars in the top and bottom rows correspond to $10(\mathbf{a}, \mathbf{c})$ and $1(\mathbf{b}, \mathbf{d}) \mu \mathrm{m}$, respectively.

Table 3. Example Intertubular Elemental Compositions (weight Percent \pm Error) Determined by EDS for each of the Dentin Samples A Through F. Note: For Sample F, Intertubular Area was Approximated Due to the Mineral Layer Formation

\begin{tabular}{|c|c|c|c|c|c|c|}
\hline Element & A & B & C & D & E & F \\
\hline \hline Carbon & $15.29(0.34)$ & $35.50(0.52)$ & $14.96(0.33)$ & $14.82(0.34)$ & $15.71(0.35)$ & $11.92(0.32)$ \\
\hline Nitrogen & Not detected & $2.26(1.33)$ & Not detected & Not detected & Not detected & Not detected \\
\hline Oxygen & $34.51(0.32)$ & $14.51(0.41)$ & $30.76(0.32)$ & $30.15(0.40)$ & $31.98(0.34)$ & $33.65(0.39)$ \\
\hline Sodium & $1.01(0.10)$ & $0.45(0.06)$ & $0.94(0.05)$ & $0.76(0.06)$ & $0.85(0.09)$ & $0.69(0.05)$ \\
\hline Magnesium & $0.96(0.07)$ & $0.47(0.07)$ & $0.28(0.03)$ & $0.41(0.06)$ & $0.27(0.04)$ & Not detected \\
\hline Phosphorous & $15.62(0.15)$ & $15.16(0.16)$ & $16.96(0.15)$ & $16.17(0.16)$ & $16.36(0.16)$ & $17.11(0.16)$ \\
\hline Calcium & $32.61(0.33)$ & $31.65(0.37)$ & $36.09(0.34)$ & $36.19(0.36)$ & $34.83(0.36)$ & $35.31(0.35)$ \\
\hline Fluorine & Not detected & Not detected & Not detected & $1.51(0.19)$ & Not detected & $1.31(0.19)$ \\
\hline
\end{tabular}

Table 4. Example Intratubular Elemental Compositions (Weight Percent \pm Error) Determined by EDS for each of the Dentin Samples A Through F. Note: For Sample F, Intratubular Location was Approximated Due to the Mineral Layer Formation

\begin{tabular}{|c|c|c|c|c|c|c|}
\hline Element & A & B & C & D & E & F \\
\hline \hline Carbon & $12.40(0.33)$ & $13.96(0.42)$ & $13.39(0.32)$ & $9.65(0.31)$ & $17.77(0.43)$ & $10.14(0.32)$ \\
\hline Nitrogen & Not detected & Not detected & Not detected & Not detected & Not detected & Not detected \\
\hline Oxygen & $32.43(0.32)$ & $7.28(0.32)$ & $29.00(0.32)$ & $30.98(0.40)$ & $15.33(0.36)$ & $33.87(0.39)$ \\
\hline Sodium & $0.80(0.10)$ & $0.41(0.06)$ & $0.75(0.05)$ & $0.78(0.05)$ & $0.65(0.11)$ & $0.60(0.05)$ \\
\hline Magnesium & $0.89(0.07)$ & $0.43(0.07)$ & $0.26(0.03)$ & $0.31(0.03)$ & $0.41(0.08)$ & Not detected \\
\hline Phosphorous & $16.90(0.16)$ & $20.79(0.24)$ & $17.86(0.15)$ & $16.72(0.16)$ & $20.09(0.21)$ & $17.25(0.16)$ \\
\hline Calcium & $36.56(0.36)$ & $57.12(0.63)$ & $38.32(0.35)$ & $39.51(0.39)$ & $45.74(0.50)$ & $36.49(0.36)$ \\
\hline Fluorine & Not detected & Not detected & Not detected & $1.75(0.19)$ & Not detected & $1.54(0.20)$ \\
\hline
\end{tabular}



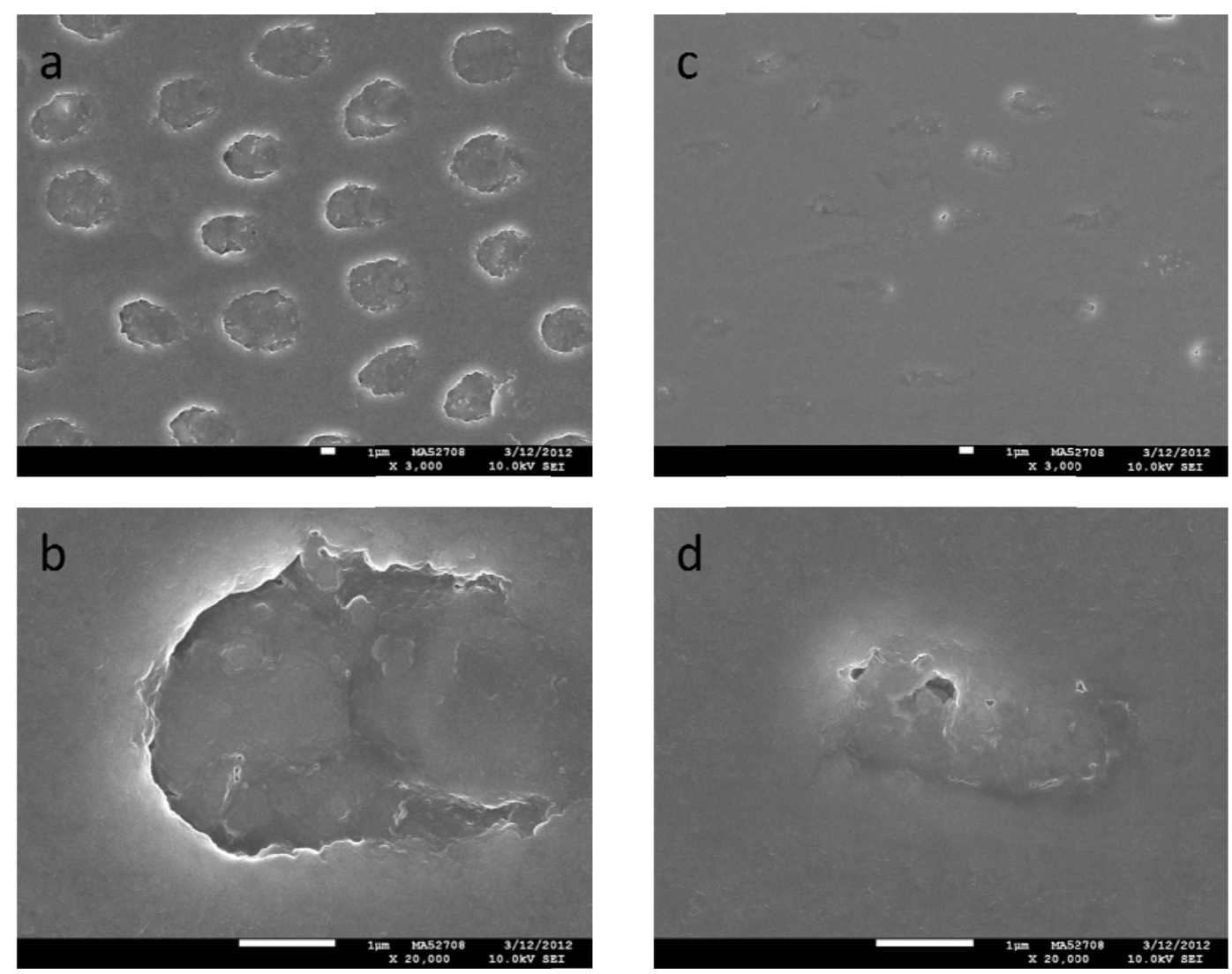

Fig. (3). SEM images of initially sound dentin treated with either water (a, b) or non-contact varnish (c, d) in the three-day pH cycling model at 3,000x and 20,000x magnification. The white scale bars in all four images correspond to $1 \mu \mathrm{m}$.
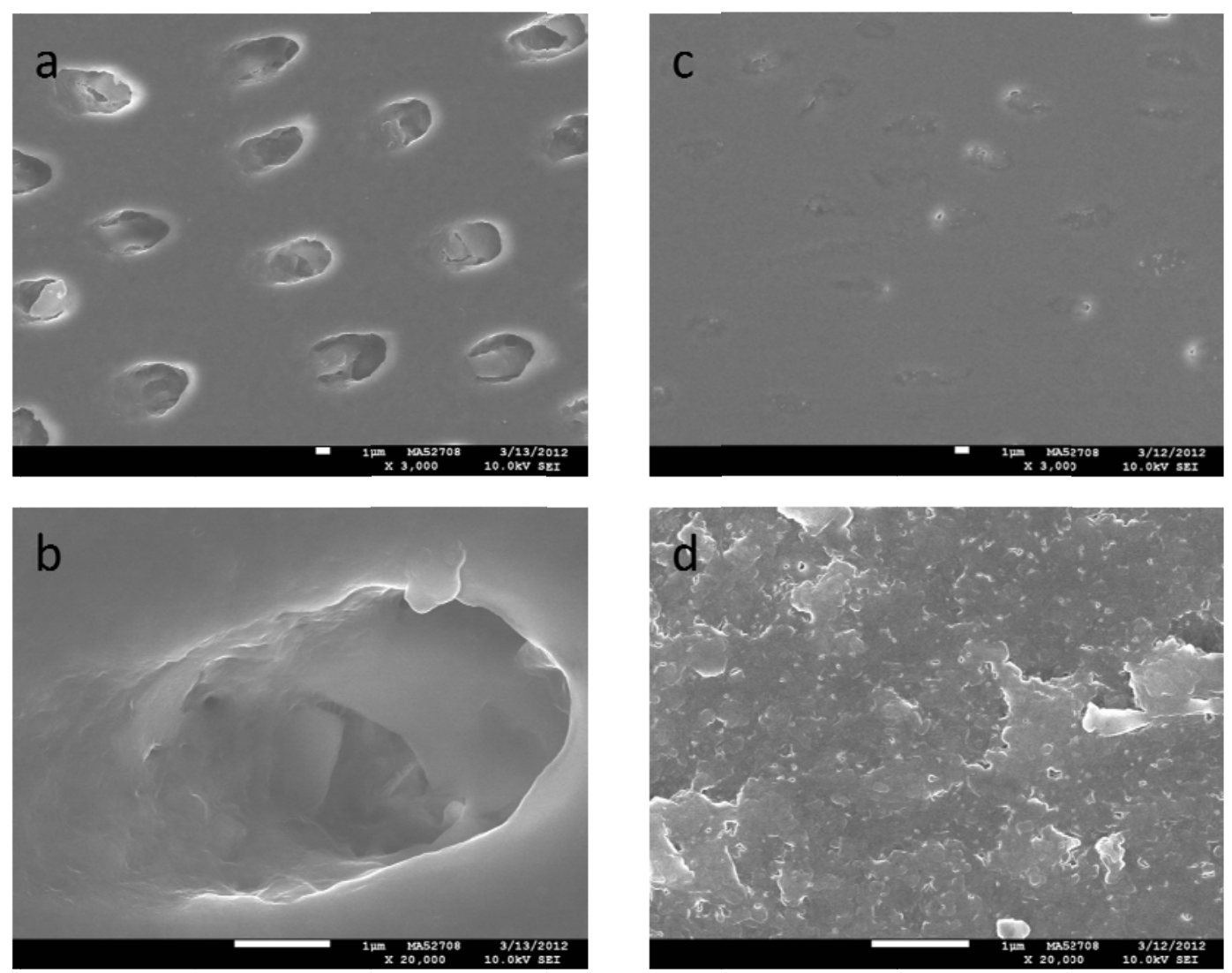

Fig. (4). SEM images of initially demineralized dentin treated with either water $(\mathbf{a}, \mathbf{b})$ or non-contact varnish $(\mathbf{c}, \mathbf{d})$ in the three-day pH cycling model at 3,000x and 20,000x magnification. The white scale bars in all four images correspond to $1 \mu \mathrm{m}$. 
distilled water (Sample E) or non-contact varnish (Sample F) are shown in Fig. (4). The water-treated specimens (Sample E) bear comparable morphology to that of baseline initially demineralized dentin (Sample B) as shown in Fig. (2c and $\mathbf{2 d}$ ), and similar composition (Tables $\mathbf{3}$ and 4). This morphology contrasts with that produced from the eluted varnish treatments (Sample F), where fluorine-containing minerallike depositions appear to coat the dentin substrate and obscure the location of dentin tubules. Clear delineation of the intertubular and intratubular regions was frustrated by the resultant mineral layer depositions; hence, the EDS data in Tables 3 and 4 are only approximations. The calcium and phosphorous weight fractions for Sample F were about 35\% and $17 \%$, respectively, and were comparable to sound baseline dentin (sample A). Additionally, this calcium-phosphate ratio of 2.1 for Sample $F$ appears consistent with the calcium-phosphate ratio for baseline sound dentin (Sample A) and suggests a comparable mineral phase may have formed.

\section{DISCUSSION}

The indication of a varnish for hypersensitivity relief was examined in this in vitro model. But while direct varnish application to patent tubules can readily thwart sensitivity from a hydrodynamic viewpoint [16], the purpose of this study was to explore mineralization of dentin through elution of mineral from a fluoride varnish containing calcium and phosphate. The absence of smear layers in this study was done purposefully in order to better visualize and probe mineralization effects on and near tubules, since they are most often associated with hypersensitivity. We utilized bovine dentin primarily because it is readily available and procedurally easier to generate specimens. We note that human dentin manifests slightly smaller diameter tubules, however, the relative concentration of dentin tubules between the two types of substrates does not differ significantly [17]. The data collected in this work compare favorably with existing SEM studies involving dentin [9-11, 18]. Additionally, the measured calcium, phosphorous, and magnesium contents of sound dentin, along with the corresponding intertubular and intratubular calcium-phosphorous ratios of about 2.1, are consistent with previous reports $[19,20]$. And despite the small sample size used, this consistency provides support for use of the EDS technique in the collection of approximate elemental compositions reported in Tables $\mathbf{3}$ and $\mathbf{4}$.

Compared to baseline sound dentin, initially demineralized dentin produced relatively higher fractions of organic material, including carbon and nitrogen, along with reduced fractions of oxygen, sodium and magnesium. These results suggest the nitrogen- and carbon-rich proteins comprising the organic matrix become particularly exposed upon loss of mineral, including sodium, magnesium, calcium and phosphorous, due to the initial demineralization with citric acid. One reason for the loss of oxygen content may be due to the loss of phosphate from apatite-like mineral, which is susceptible to dissolution, for instance, with citric acid [21]. Studies utilizing secondary ion microscopy have shown the tubular and peritubular regions to be magnesium rich [22]. When exposed to acid challenges, it is possible that loss of magnesium may occur and this may contribute to the well-resolved outlines of tubules in Figs. (2, 3, and 4).
We note that a possible explanation for the detection of a relatively high calcium content, such as that observed for initially demineralized dentin (i.e. Samples B and E), may be due to a relative $\mathrm{x}$-ray absorption effect, where loss of intratubular material leads to less overall absorption of x-rays; in turn, this could lead to a higher calcium signal that is not reflective of a higher calcium concentration. Additionally, the slight increase in phosphorous content for these initially demineralized specimens may be due to a combination of relatively higher signal due to matrix loss (as discussed for calcium) along with the resultant exposure of phosphoproteins, such as phosphophoryn, comprising the dentin tubules [23-25]. Phosphoproteins are good chelators of calcium, and may also be contributing (albeit perhaps marginally) to the observed weight fractions.

Previous studies have focused on the ability of varnishes to release fluoride and deliver fluoride to the enamel surface [12-14]. While fluoride release and uptake are important characteristics in this study the effects of dentin morphology from ions released from a fluoride varnish were assessed. The $5 \% \mathrm{NaF}$ varnish used in this study is designed for sustained release of fluoride, calcium and phosphate and has been shown to deliver about $6.6 \mathrm{ppm} \mathrm{F}^{-}$and $1.4 \mathrm{ppm} \mathrm{F}^{-}$to the oral environment after one and four hours, respectively, after application to maxillary teeth in vivo [26]. These in vivo measurements influenced the one-hour treatment design of this in vitro protocol, although we recognize in vitro modeling has inherent limitations compared to clinical evaluations [27]. Still, we believe the results from this study may provide insight regarding the ability of mineralizing agents, such as fluoride, to integrate with dentinal tissue through elution (as opposed to direct contact of varnish on the substrate).

The high-resolution SEM imaging revealed that the morphology of dentin (initially either sound or demineralized) was changed when exposed to the $5 \% \mathrm{NaF}$ varnish system. The purpose of this study was not to distinguish whether the observed effects are derived mostly from fluoride or the tricalcium phosphate, or whether they mineralize the dentin substrates equally, since such control varnish systems were not included. While future studies might employ the use of these controls in a comparable rosin-based varnish system to learn further about each mineralizing agent, the present study was designed to evaluate whether a commercial 5\% NaF varnish can mineralize dentin surfaces through an elution mechanism. Although there are a variety of fluoride varnishes commercially available, one cannot confirm with certainty whether the performance of other varnishes would match those of the $\mathrm{Vanish}^{\circledR} 5 \% \mathrm{NaF}$ varnish explored here. Still, the model described in this research might contribute to the evaluation and understanding of currently marketed or developmental 5\% $\mathrm{NaF}$ varnish systems and their role in hypersensitivity relief.

\section{CONCLUSIONS}

While in vitro models are naturally imperfect as they relate to clinical settings, still they provide important insight into the benefits and limitations of dental preparations. The observational results in the current study may provide support to clinicians' recommendations of a fluoride varnish for 
sensitivity relief. In particular, we have shown acid-resistant remineralization of dentin substrates can be achieved without direct varnish contact. Our observations might be strengthened with support from follow-on in vitro studies with larger sample sizes, as well as an intra-oral study for clinical evaluation. These pilot results support the role of varnishes as a reservoir for release of bioavailable ions, especially to regions where varnish has not been applied to the teeth, and might extend to other fluoride-containing varnish systems, with or without calcium phosphates or other mineralizing agents.

\section{ACKNOWLEDGEMENTS}

We kindly acknowledge technical support from Dakota Blanken and Katherine Frederick for dentin specimen preparation. This research was partially supported by grant number R44DE018576 from the National Institutes of Dental \& Craniofacial Research (NIDCR).

\section{CONFLICT OF INTEREST/DISCLOSURE STATEMENT}

The content is solely the responsibility of the authors and does not necessarily represent the official views of the NIDCR, the National Institutes of Health or 3M ESPE. Mr. Mackey is the Quality Director and Laboratory Manager and Dr. Robert L. Karlinsey is the CEO and Principle Investigator at Indiana Nanotech, which has a commercial relationship with 3M ESPE. Dr. Craig Schwandt is a Senior Research Scientist at McCrone Associates, Inc.

\section{REFERENCES}

[1] Addy M, Smith SR. Dentin hypersensitivity: an overview on which to base tubule occlusion as a management concept. J Clin Dent 2010; 21(Spec Iss): 25-30.

[2] Orchardson R, Gillam DG. Managing dentin hypersensitivity. J Am Dent Assoc 2006; 137: 990-8.

[3] Gillam DG, Bulman JS, Eijkman MAJ, Newman HN. Dentists' perceptions of dentine hypersensitivity and knowledge of its treatment. J Oral Rehabil 2002; 29: 219-25.

[4] FDA. Dental devices; prosthetic devices. Fed Regist 1996; 8: $302-$ 11.

[5] Marinho VCC, Higgins JPT, Logan S, Sheiham A. Fluoride varnishes for preventing dental caries in children and adolescents. Cochrane Database Syst Rev 2002; (3): CD002279.

[6] CDC. Recommendations for using fluoride to prevent and control dental caries in the United States. MMWR 2001; 50(RR14).

[7] Burwell A, Jennings D, Muscle D, Greenspan DC. NovaMin ${ }^{\circledR}$ and dentin hypersensitivity: In vitro evidence of efficacy. J Clin Dent 2010; 21(Spec Iss): 66-71.

[8] Greenhill JD, Pashley DH. The effects of desensitizing agents on the hydraulic conductance of human dentin in vitro. J Dent Res 1981; 60: 686-98.
[9] Karlinsey RL, Mackey AC, Schwandt CS, Walker TJ. SEM evaluation of demineralized dentin treated with professional-strength $\mathrm{NaF}$ topical pastes. Am J Dent 2011; 24: 357-62.

[10] Sauro S, Gandolfi MG, Prati C, Mongiorgi R. Oxalate-containing phytocomplexes as dentine desensitisers: an in vitro study. Arch Oral Biol 2006; 51: 655-64.

[11] White DJ, Lawless MA, Fatade A, et al. Stannous fluoride/sodium hexametaphosphate dentifrice increases dentin resistance to tubule exposure in vitro. J Clin Dent 2007;18: 55-9.

[12] Flanigan P-J, Vang F, Pfarrer AM. Lesion remineralization and acid resistance using four varnishes in vitro. J Dent Res 2011; 90(Spec Iss A): Abstract 2139

[13] Schemehorn BR, Wood GD, McHale W, Winston AE. Comparison of fluoride uptake into tooth enamel from two fluoride varnishes containing different calcium phosphate sources. J Clin Dent 2011; 22: 51-4.

[14] Attin T, Grieme R, Paque F, Hannig C, Buchalla W, Attin R. Enamel fluoride uptake of a novel water-based fluoride varnish Arch Oral Biol 2005; 50: 317-22.

[15] Karlinsey RL, Mackey AC, Walker ER, Frederick KE. Preparation, characterization and in vitro efficacy of an acid-modified $\beta$-TCP material for dental hard-tissue remineralization. Acta Biomater 2010; 6: 969-78.

[16] Pashley DH. Dentin permeability, dentin sensitivity, and treatment through tubule occlusion. J Endod 1986; 12: 465-74.

[17] Schilke R, Lisson JA, BauB O, Geurtsen W. Comparison of the number and diameter of dentinal tubules in human and bovine dentine by scanning electron microscopic investigation. Arch Oral Biol 2000; 45: 355-61.

[18] Salian ST, Kulkarni S, LaTorre G. A randomized controlled clinical study evaluating the efficacy of two desensitizing dentifrices. J Clin Dent 2010; 21(Spec Iss): 82-7.

[19] Derise NL, Ritchey SJ, Furr AK. Mineral composition of normal human enamel and dentin and the relation of composition to dental caries: I. Macrominerals and comparison of methods of analyses. J Dent Res 1974; 53: 847-52.

[20] Burnett GW, Zenewitz JA. Studies of the composition of teeth: VIII. The composition of human teeth. J Dent Res 1958; 37: 590600.

[21] Misra DN. Interaction of citric acid with hydroxyapatite: surface exchange of ions and precipitation of calcium citrate. J Dent Res 1996; 75: 1418-25.

[22] Lefevre R, Frank RM, Voegel JC. The study of human dentine with secondary ion microscopy and electron diffraction. Calcif Tissue Int 1976; 19: 251-61.

[23] Stetler-Stevenson WG, Veis A. Bovine dentin phosphophoryn: composition and molecular weight. Biochemistry1983; 22: 432635 .

[24] Stetler-Stevenson WG, Veis A. Bovine dentin phosphophoryn: calcium ion binding properties of a high molecular weight preparation. Calcif Tissue Int 1987; 40: 97-102.

[25] Lee SL, Veis A, Glonek T. Dentin phosphoprotein: an extracellular calcium-binding protein. Biochemistry 1977; 16: 2971-9.

[26] 3M ESPE. Vanish 5\% Sodium Fluoride White Varnish with TriCalcium Phosphate - Technical Product Profile. Available at: http://multimedia.3m.com $/ \mathrm{mws} /$ mediawebserver?mwsId $=66666 \mathrm{Uu}$ ZjcFSLXTtnxf6mXMXEVuQEcuZgVs6EVs6E666666-$\& \mathrm{fn}=$ vanish_tpp.pdf [Accessed July 16, 2012].

[27] White DJ. The application of in vitro models to research on demineralization and remineralization of the teeth. Adv Dent Res 1995; 9: 175-93. \begin{tabular}{lll}
\hline Received: June 25, 2012 & Revised: August 02, 2012 & Accepted: August 02, 2012 \\
(C) Karlinsey et al.; Licensee Bentham Open. & \\
This is an open access article licensed under the terms of the Creative Commons Attribution Non-Commercial License \\
(http://creativecommons.org/licenses/by-nc/3.0/) which permits unrestricted, non-commercial use, distribution and reproduction in any medium, provided the
\end{tabular} work is properly cited. 